\title{
Flooding-Associated Soft Rot of Sweetpotato Storage Roots Caused by Distinct Clostridium Isolates
}

\author{
Washington L. da Silva, ${ }^{1,2}$ Kuei-Ting Yang, ${ }^{3}$ Gregg S. Pettis, $,{ }^{1,3},{ }^{\dagger}$ Natasha R. Soares,${ }^{3}$ Rebecca Giorno, ${ }^{4}$ and Christopher A. Clark ${ }^{1}$ \\ ${ }^{1}$ Department of Plant Pathology and Crop Physiology, Louisiana State University Agricultural Center, Baton Rouge, LA 70803 \\ ${ }^{2}$ The Connecticut Agricultural Experiment Station, Department of Plant Pathology and Ecology, New Haven, CT 06511 \\ ${ }^{3}$ Department of Biological Sciences, Louisiana State University, Baton Rouge, LA 70803 \\ ${ }^{4}$ School of Biological Sciences, Louisiana Tech University, Ruston, LA 71272
}

\begin{abstract}
Flooding of sweetpotatoes in the field leads to development of soft rot on the storage roots while they remain submerged or on subsequent harvest and storage. Incidences of flooding after periods of intense rainy weather are on the rise in the southeastern United States, which is home to the majority of sweetpotato production in the nation. In an effort to characterize the causative agent(s) of this devastating disease, here we describe two distinct bacterial strains isolated from soft-rotted sweetpotato storage

and both were confirmed to cause soft rot disease on sweetpotato and other vegetable crops. Despite these common features, the isolates were distinguishable by several phenotypic and biochemical properties, and phylogenetic analysis placed them in separate well-supported clades within the genus. Overall, our results demonstrate that multiple plantpathogenic Clostridium species can cause soft rot disease on sweetpotato and suggest that a variety of other plant hosts may also be susceptible.
\end{abstract} roots retrieved from an intentionally flooded field. Both of these anaerobic spore-forming isolates were identified as members of the genus Clostridium based on sequence similarity of multiple housekeeping genes,
Keywords: climate/weather effects, epidemiology, pathogen diversity, prokaryotes
Pectolytic clostridia cause soft rot in potato, Solanum tuberosum L. (Campos et al. 1982; Lund 1972; Perombelon et al. 1979), and yam, Dioscorea rotundata (Obi 1981), and they are associated with wetwood diseases (Schink et al. 1981) and cause cavity spot in carrots (Perry and Harrison 1977). The occurrence of these diseases is linked to wet seasons and poorly drained soils with restricted aeration. Although pectolytic clostridia have been linked with soft rot of various crops and plants, additional characterization of these pathogens has been minimal. The only species described is Clostridium puniceum, which causes potato soft rot (potato slimy rot) (Lund et al. 1981; Shabuer et al. 2015). C. puniceum is an anaerobic, spore-forming, rod-shaped, pink-pigmented pectolytic bacterium (Lund et al. 1981).

The production of sweetpotatoes in the United States is largely concentrated in the southeast, where rainfall is abundant, and there is a persistent threat of hurricanes, tropical storms, and other wet weather during much of the growing season (https://www.usda. gov/media/blog/2017/01/05/us-sweet-potato-production-swells). sweetpotato storage roots exposed to flooding and associated anoxic conditions frequently develop soft rot, which can appear in the flooded fields or on subsequent storage. In states such as Louisiana, annual sweetpotato crop losses of $50 \%$ or more owing to soft rot have been documented, for example, after Hurricanes Gustav and Ike in 2008 (Louisiana Summary: Agriculture and Natural Resources

${ }^{\dagger}$ Corresponding author: G. S. Pettis; gpettis@1su.edu

W. L. da Silva and K.-T. Yang contributed equally to this work.

Funding: This work was supported by U.S. Department of Agriculture National Institute of Food and Agriculture Hatch project no. LAB94337 and a Louisiana Board of Regents Pfund award.

*The $\boldsymbol{e}$-Xtra logo stands for "electronic extra" and indicates that one supplementary figure and one supplementary table are published online.

The author(s) declare no conflict of interest.

Accepted for publication 27 June 2019.

(C) 2019 The American Phytopathological Society
2009, LSU AgCenter; https://www.lsuagcenter.com). Identification of the causative agent(s) of soft rot in sweetpotato is an important first step toward development of an effective disease management strategy that reduces losses associated with flooding. Here, we describe the isolation of two bacterial strains from sweetpotato soft rot lesions and show that these strains are capable of inducing this disease on inoculations to asymptomatic storage roots. Phenotypic, biochemical, and genotypic characterizations support the hypothesis that these isolates represent distinct Clostridium species that are capable of causing soft rot disease on a range of plant hosts.

\section{Materials and Methods}

Bacterial media. All media in this study were reduced by incubating the plates for 4 days in an anaerobic jar (BD GasPakTM 100, Anaerobic Jars; Becton Dickinson Microbiology Systems) in an atmosphere containing $\mathrm{H}_{2}: \mathrm{CO}_{2}\left(90: 10\right.$ by volume) at $32^{\circ} \mathrm{C}$ before being used. Streaked plates were also incubated in this anaerobic jar to maintain anaerobiosis. Nutrient dextrose agar plus $0.05 \%$ cysteine hydrochloride (NDAC) was used for initial isolation and morphological characterization of strains and where noted, for biochemical plate assays (Lund 1972). Potato infusion agar (PIA) plus $0.05 \%$ cysteine hydrochloride was also used for morphological characterization (Lund et al. 1981). Potato infusion medium (PIM) plus $0.05 \%$ cysteine hydrochloride was used for preservation of the isolates (Holdeman et al. 1977). Pectinase activity was evaluated using double-layer pectate medium (DLPM) (Lund 1969). Tryptoneyeast extract-glucose (TYG) broth (Garnier and Cole 1986) was used for growth of isolates for the purpose of genomic DNA (gDNA) isolation.

Bacterial isolations and tests for pathogenicity based on Koch's Postulates. Although soft rot of sweetpotato is common during natural flooding, logistical concerns, such as predicting the timing and magnitude of such events, as well as gaining access to affected crops in often large and unsafe flood zones made bacterial isolation from these natural sites impractical. Therefore, bacteria were isolated from sweetpotato storage roots with soft rot symptoms obtained from plants growing in a field that was intentionally flooded 2 weeks before harvest. In total, there were eight samples from eight different rotting storage roots of the cultivar Evangeline (one sample per storage root and one storage root per plant). Portions of the 
decaying tissue were suspended in sterile distilled water and streaked on NDAC. Streaked plates were inverted and fumigated with $1 \mathrm{ml}$ of chloroform for $10 \mathrm{~min}$ to eliminate nonspore-forming bacteria (Bauernfeind and Burrows 1978). Then, the plates were incubated in an anaerobic jar for 7 days at $32^{\circ} \mathrm{C}$. Isolated bacterial colonies from these plates were restreaked on NDAC and incubated in aerobic and anaerobic atmospheres. Colonies from isolates that grew in the anaerobic environment but not in the aerobic environment were collected and preserved in screw-cap tubes containing PIM with $0.05 \%$ cysteine hydrochloride for additional evaluations.

To verify pathogenicity based on Koch's Postulates, pure culture inocula were prepared by suspending bacterial cells that had been growing as colonies for 7 days on NDAC in sterile distilled water amended with $0.05 \%$ cysteine and then, diluting the suspensions to an optical density of $0.1\left(\sim 1 \times 10^{8} \mathrm{CFU} \mathrm{ml}^{-1}\right)$. For each isolate, 10 storage roots (Evangeline) were inoculated, and 10 control storage roots were mock inoculated with sterile distilled water plus $0.05 \%$ cysteine. Whole asymptomatic sweetpotato storage roots were washed with tap water, surface disinfected with $1 \% \mathrm{NaOCl}$ for $10 \mathrm{~min}$, and inoculated by inserting and leaving a pipette tip containing $50 \mu \mathrm{l}$ of inoculum suspension in each storage root. The storage roots were then individually wrapped with moist paper towels, placed in a plastic bag that was tied shut, and incubated at $30^{\circ} \mathrm{C}$ for 7 days. The same procedure was used for inoculation of potato tubers, onion bulbs, and carrot roots, which were purchased from a local grocery store. Reisolation of bacteria was performed from inoculated decaying tissue on NDAC as described above.

Differentiation of isolates. Pectolytic ability was evaluated by streaking bacterial cells kept in PIM plus $0.05 \%$ cysteine hydrochloride onto DLPM plates (Lund 1969). Streaked plates were incubated for 7 days at $32^{\circ} \mathrm{C}$ in an anaerobic jar. After incubation, the plates were inspected for pit formation, which is an indication of pectin degradation. Colonies that formed pits were classified as pectolytic, whereas colonies that did not form pits were considered negative for pectolytic activity. Amylase, caseinase, or cellulase activities were assayed on NDAC containing $1 \%$ soluble starch, $1 \%$ nonfat milk, or $1 \%$ carboxymethyl cellulose, respectively. Streak plates for these assays were incubated for 5 days at $32^{\circ} \mathrm{C}$ in an anaerobic jar. NDAC plates containing $1 \%$ nonfat milk were then examined for clear zones of hydrolysis around colonies to determine if caseinase was being produced (Pommerville 2011). The NDAC plates containing $1 \%$ starch were flooded with iodine and then, examined after $15 \mathrm{~min}$ for clear zones of hydrolysis to ascertain if amylase was being produced (McFaddin 2000). Finally, NDAC plates containing carboxymethyl cellulose were flooded with Congo red $(1 \mathrm{mg} / \mathrm{ml})$ for $15 \mathrm{~min}$, the Congo red solution was poured off, and the plates were then flooded with $1 \mathrm{M} \mathrm{NaCl}$ for another $15 \mathrm{~min}$. The plates were then examined for zones of hydrolysis to determine if cellulase was being synthesized (Teather and Wood 1982). Plate assays were repeated three times.

Bacterial endospores were initially analyzed by using a differential bacterial staining protocol (Reynolds et al. 2009) with some modifications. Briefly, a loop of bacterial cells grown in PIM plus $0.05 \%$ cysteine hydrochloride was spread on a microscope slide and completely air dried. The smear was heat fixed by moving the slide quickly over a Bunsen burner flame three to four times. Then, the slide was covered with a small piece of paper towel and flooded with malachite green dye solution $(0.5 \mathrm{~g}$ of malachite green in $100 \mathrm{ml}$ of distilled water). The slide was left for $5 \mathrm{~min}$ on a wire screen on top of a beaker containing boiling water. The slide was then washed thoroughly with tap water, flooded with safranin dye solution $(2.5 \mathrm{~g}$ of safranin $\mathrm{O}$ in $100 \mathrm{ml}$ of $95 \%$ [vol/vol] ethanol), and left for $1 \mathrm{~min}$. Finally, the slide was washed thoroughly with tap water, blotted dry with paper towels, and observed with the aid of a light microscope under a $100 \times$ oil immersion objective. Pictures were taken with an Olympus DP72 microscope digital camera (Olympus Corporation).

Bacterial cell measurements were taken using differential interference contrast (DIC) microscopy. A 10- $\mu$ l aliquot of bacterial suspension grown in PIM plus $0.05 \%$ cysteine hydrochloride was placed on a microscope slide, covered with a slide cover, and directly observed with a Leica TCS SP2 Spectral Confocal microscope in the Socolofsky Microscopy Center, Department of Biological Sciences, Louisiana State University (LSU).

Transmission electron microscopy. Spore suspensions were prepared by plating 3- to 4-day-old cultures onto PIA containing $0.05 \%$ cysteine hydrochloride, and plates were then incubated for 10 days at $30^{\circ} \mathrm{C}$ under anaerobic conditions. Spores were collected and washed with ice-cold sterile distilled water at $14,000 \mathrm{rpm}$ for $5 \mathrm{~min}$. Spore suspensions were refrigerated overnight to lyse vegetative cells. The overnight spore suspensions were washed 10 additional times as before with ice-cold distilled water to remove intact cells and cell debris. Spores were resuspended in $0.25 \mathrm{ml}$ of distilled water, and this mixture was then carefully added to the top of $1 \mathrm{ml}$ of $50 \%$ glucose in an Eppendorf tube. After centrifugation at 8,000 rpm for $5 \mathrm{~min}$, the pelleted spores were washed with distilled water an additional 5 to 10 times to remove any remaining intact cells, cell debris, and glucose. Glucose gradient and washing steps were repeated as necessary until the spores were judged to be $>99 \%$ pure as determined by phase contrast microscopy.

Purified spores were resuspended in fixative $(0.1 \mathrm{M}$ cacodylate buffer [pH 7.4] containing $2 \%$ paraformaldehyde and $2.5 \%$ glutaraldehyde) in individual tubes and incubated for $10 \mathrm{~min}$. The supernatant was removed after centrifugation. Spores were mixed with the same fixative and refrigerated overnight. Spores were pelleted by centrifugation, and the supernatant was removed. The spore pellets were mixed with an equal amount of $3 \%$ agarose. The spore agarose mixture was placed on a light microscopy slide and cut into cubes after it solidified. The cubes were placed into a glass vial filled with $0.1 \mathrm{M}$ cacodylate buffer ( $\mathrm{pH}$ 7.4) followed by five washes for 20 min each with $0.1 \mathrm{M}$ cacodylate buffer containing $0.08 \mathrm{M}$ glycine, including one overnight wash. Spores were fixed with $2 \%$ osmium tetroxide in $0.1 \mathrm{M}$ cacodylate buffer ( $\mathrm{pH} 7.4$ ) in the dark for $2 \mathrm{~h}$. The fixed spores were washed with distilled water three times for 5 min each. Spores were incubated in 50, 70, 80, and 90\% ethanol for $20 \mathrm{~min}$ each followed by three washes of $20 \mathrm{~min}$ each in $100 \%$ ethanol. Spores were infiltrated for $2 \mathrm{~h}$ in a 1:1 mixture of $100 \%$ ethanol and LR white resin (Millipore Sigma), and then, they were infiltrated in $100 \%$ LR white resin for $2 \mathrm{~h}$. The spore pellets within the resin without bubbles were dissected and transferred into the bottom of Beem capsules, which were then incubated in a $65^{\circ} \mathrm{C}$ oven for 24 h. Thin sections ( $90 \mathrm{~nm}$ ) obtained with a Leica EM UC7 Microtome were placed on glow discharge carbon-coated grids and stained with $2 \%$ uranyl acetate and lead citrate. Grids were analyzed with a JEOL JEM-1400 transmission electron microscope located in LSU's Shared Instrumentation Facility.

gDNA extraction and PCR amplification of housekeeping genes. Purification of gDNA was performed as described previously (Bouillaut et al. 2011) with modifications. A colony of LSU-B1 or -B7 was inoculated into $3 \mathrm{ml}$ of TYG broth and incubated in a $30^{\circ} \mathrm{C}$ anaerobic chamber for 2 to 3 days; $1.5 \mathrm{ml}$ of cell culture was harvested by centrifugation for $10 \mathrm{~min}$ at $6,000 \mathrm{rpm}$ and $4{ }^{\circ} \mathrm{C}$. The pellet was washed with $1 \mathrm{ml}$ of Tris-EDTA (TE) buffer (10 mM Tris-HCl, $1 \mathrm{mM}$ EDTA [pH 8.0]) by vortexing, and the cell suspension was recentrifuged as before. The cell pellet was resuspended in $200 \mu$ l of gDNA buffer ( $34.23 \mathrm{~g}$ of sucrose in a final volume of $100 \mathrm{ml}$ of TE buffer), and $50 \mu \mathrm{l}$ of lysozyme solution $(50 \mathrm{mg} / \mathrm{ml})$ was added with subsequent incubation at $37^{\circ} \mathrm{C}$ for $\sim 2 \mathrm{~h}$. Then, $100 \mu \mathrm{l}$ of $20 \%$ Sarkosyl, $15 \mu \mathrm{l}$ of RNase A $(10 \mathrm{mg} / \mathrm{ml})$, and $15 \mu l$ of proteinase $\mathrm{K}(10 \mathrm{mg} / \mathrm{ml})$ were added, and incubation was continued at $37^{\circ} \mathrm{C}$ for an additional $30 \mathrm{~min}$. The volume was adjusted to $600 \mu \mathrm{l}$ with TE buffer, and extraction with an equal volume of phenol:chloroform:isoamyl alcohol (25:24:1) was performed. Extraction of the aqueous phase was repeated until there was no visible interface. The aqueous phase was then extracted a final time with an equal volume of chloroform, and gDNA was precipitated by adding $50 \mu \mathrm{l}$ of $3 \mathrm{M}$ sodium acetate ( $\mathrm{pH}$ 5.2) and $150 \mu \mathrm{l}$ of cold $95 \%$ ethanol. The tube was centrifuged at 14,000 rpm at room temperature for $5 \mathrm{~min}$ followed by washing of the pellet with $500 \mu \mathrm{l}$ of $70 \%$ ethanol. DNA pellets were resuspended in $50 \mu$ l of sterile distilled water.

To obtain gyrA and groEL sequences for phylogenetic analysis, fragments of 793 and $999 \mathrm{bp}$, respectively, were amplified from 
gDNA using the primers previously described (Bouvet et al. 2014). PCR reactions were performed in $25-\mu$ l reaction mixtures containing $5 \mu \mathrm{l}$ of $5 \times$ Q5 Reaction Buffer (New England BioLabs), $1 \mu \mathrm{l}$ of $10 \mathrm{mM}$ dNTPs, $0.25 \mu \mathrm{l}$ of Q5 DNA polymerase (2 units), $0.63 \mu \mathrm{l}$ of $20 \mu \mathrm{M}$ each primer, and $100 \mathrm{ng}$ of gDNA. PCR amplification began with an initial denaturation period of $98^{\circ} \mathrm{C}$ for $30 \mathrm{~s}$, which was followed by 30 cycles of $98^{\circ} \mathrm{C}$ for $10 \mathrm{~s}, 61^{\circ} \mathrm{C}$ for $30 \mathrm{~s}$, and $72^{\circ} \mathrm{C}$ for $30 \mathrm{~s}$ and a final extension period of $72^{\circ} \mathrm{C}$ for $2 \mathrm{~min}$. Finished PCR reactions were examined by electrophoresis on $1 \%$ agarose gels, and amplicons were purified by using a Monarch DNA Gel Extract Kit (New England BioLabs). Sequencing of purified amplicons was performed at Eurofins Genomics USA.

Phylogenetic analyses. For phylogenetic analysis of gyrA, 645-bp (for LSU-B1) and 636-bp (for LSU-B7) regions of the respective amplicons were subjected to separate BLASTn searches. The top 50 sequence matches from each search were combined, and any duplicate sequences (i.e., with the same accession number) were eliminated. The remaining set of homologous sequences along with the LSU-B1 and LSU-B7 gyrA query sequences and the respective sequence for the outgroup Bacillus subtilis were aligned using MUSCLE v3.8.31 (Edgar 2004). The default settings of Gblocks (Castresana 2000) were then used to trim the alignments, keeping the conserved portions. Phylogenetic trees were constructed by maximum likelihood using the PhyML software v3.3 (Guindon and Gascuel 2003) with a general time-reversible plus gamma substitution model, and bootstrap support (1,000 replicates) was determined with the nearest neighbor interchange branch-swapping method. For figure preparation, clades within trees were manually trimmed to eliminate excessive numbers of strains of a given species, but no species per se were eliminated. The procedure for phylogenetic analysis of groEL was identical to that detailed for $g y r A$ except that 249-bp regions of the groEL amplicons were used for analysis as described (Bouvet et al. 2014). Strains appearing in the gyrA and/or groEL phylogenetic trees are also listed with their GenBank accession numbers in Supplementary Table S1.

Extraction and analysis of fatty acids. LSU-B1 and LSU-B7 cells were harvested after anaerobic growth on PIA for 3 days. Whole-cell fatty acid methyl ester (FAME) extractions were prepared according to standard protocols developed for the Microbial Identification System (MIDI). In brief, lipids were saponified by adding $1 \mathrm{ml}$ of $3.75 \mathrm{M} \mathrm{NaOH}$ in methanol to each sample tube. Mixtures were then heated in a $100^{\circ} \mathrm{C}$ water bath for $5 \mathrm{~min}$. The tubes were vigorously vortexed for 5 to $10 \mathrm{~s}$ and heated for an additional $25 \mathrm{~min}$. The samples were methylated by adding $2 \mathrm{ml}$ of $3.25 \mathrm{M} \mathrm{HCl}$ in methanol, and after a brief vortexing, they were incubated in a $80^{\circ} \mathrm{C}$ water bath for $10 \mathrm{~min}$. FAMEs were extracted from the cooled solution by adding $1.25 \mathrm{ml}$ of hexane and placing on a rotator for $10 \mathrm{~min}$. The aqueous (lower) phase was pipetted out and discarded. The organic phase was washed using $3 \mathrm{ml}$ of $0.3 \mathrm{M} \mathrm{NaOH}$ and transferred to a glass gas chromatography (GC) vial for analysis by GC.

Nucleotide sequence accession numbers. The gyrA and groEL allele sequences used for phylogenetic analysis of the isolates described in this study were deposited in the GenBank database under accession numbers MK479281 to MK479284.

\section{Results}

Sweetpotato soft rot isolates displayed distinctive phenotypes. Two distinct groups of bacteria were consistently isolated from decaying tissue of soft-rotted Evangeline storage roots grown in an intentionally flooded field. One representative isolate from each group, designated LSU-B1 and LSU-B7, was selected for additional investigation. Both isolates had a gram-positive reaction, grew on media incubated in an anaerobic environment but not on media exposed to air, and formed subterminal endospores, indicating that they likely belonged to the genus Clostridium (Lund and Kelman 2001). Aside from these common features, the characteristics of the isolates differed considerably. LSU-B1 consistently produced smaller colonies on all media tested (data not shown). Although the vegetative cells of both isolates were rod shaped, the cells of LSU-B1 were smaller in length (3 to $5 \mu \mathrm{m}$ ) compared with those of LSU-B7
(5 to $11 \mu \mathrm{m}$ ) as measured by DIC microscopy, and LSU-B1 produced fewer endospores on PIM as determined by differential malachite green staining (data not shown).

Spores produced by strains LSU-B1 and LSU-B7 were examined in greater detail by using transmission electron microscopy. Spores for both isolates had the same basic layers: that is, an exosporium, interspace, coat, cortex, and core (Fig. 1). The exosporium for both consisted of a basal layer, and coats appeared to be similar in thickness. As with their vegetative cells, there were also features that distinguished the spores of each strain. The coat of LSU-B7 consistently displayed a pronounced scalloped appearance, and there was a considerable amount of dark grainy material at the outer edge of the cortex, which often appeared to be concentrated under each scallop point. Although the coat of LSU-B1 occasionally showed some evidence of scalloping, it was less pronounced and not as regularly spaced as that of LSU-B7. Dark grainy material was also sometimes evident for LSU-B1 but in lesser amounts compared with LSU-B7. Because the method of spore preparation was the same for both strains and the inner spore layers appeared rounded with no evidence of shrinkage or collapse, we believe that the scalloped appearance of LSU-B7 spores (and to a lesser extent, LSU-B1 spores) represents their natural morphology rather than an artifact of the transmission electron microscopy procedure. Finally, LSU-B1 spores showed evidence of electron-dense material projecting from the coat and into the interspace (arrows in Fig. 1A and B). In at least some instances, these projections appeared to touch both the coat and exosporium.

Plates assays to detect various biochemical functions potentially related to pathogenicity further distinguished the two isolates. Only LSU-B1 formed pits on DLPM, which was evidence that LSU-B1, but not LSU-B7, displayed pectolytic activity on this medium (Table 1). Similarly, only LSU-B1 produced zones of hydrolysis on NDAC medium containing starch, which was indicative of amylase function. In contrast, only LSU-B7 showed evidence of caseinase and cellulase activities on NDAC containing nonfat milk and carboxymethyl cellulose, respectively (Table 1).

LSU-B1 and LSU-B7 induced soft rot in asymptomatic sweetpotatoes and other vegetables. To verify the pathogenicity of these isolates, they were first individually inoculated into asymptomatic Evangeline sweetpotato storage roots. All storage roots inoculated with either LSU-B1 or LSU-B7 developed severe soft rot after 7 days of incubation in a hypoxic environment, whereas noninoculated control roots remained intact and free of soft rot lesions (Fig. 2). Previous studies on plant pathogenic Clostridium isolates have focused on individual plant hosts; thus, nothing is known about the host range of individual isolates. Here, we found that, when either LSU-B1 or LSU-B7 was inoculated in potato tubers, onion bulbs, and carrot roots, these vegetables were completely rotted after 5 days of incubation (Fig. 3). None of the mock-inoculated vegetables developed soft rot (Fig. 3). In all pathogenicity assays involving either sweetpotato storage roots or the other vegetables tested, the inoculated bacterial isolates were reisolated on NDAC agar from decaying tissue (data not shown)

Confirmation of LSU-B1 and LSU-B7 as Clostridium isolates. Relatedness of isolates LSU-B1 and LSU-B7 to members of the genus Clostridium was first examined by comparative analysis involving the housekeeping gene gyrA, which has been used in previous phylogenetic studies of Clostridium spp. (Bouvet et al. 2014). BLASTn search results were used to construct phylogenetic trees consisting of the LSU-B1 and LSU-B7 gyrA query sequences along with their closest matching sequences and $B$. subtilis, which was used as the outgroup. As shown in Figure 4, LSU-B1 clustered with Clostridium saccharoperbutylacetonicum in a well-supported clade (97.8\%), whereas LSU-B7 was found likewise within another wellsupported clade $(94.6 \%)$ with Clostridium saccharobutylicum. To confirm and extend these results, phylogenetic analysis involving another housekeeping gene ( $g r o E L)$ yielded nearly identical results (Supplementary Fig. S1), and analysis of a third gene (dnaK) also resulted in similar clustering of these strains (data not shown). Interestingly, $C$. puniceum was not among the top 50 matching sequences for any of these genes for either LSU-B1 or LSU-B7, with similarity 
scores well below the threshold (data not shown). Thus, the phylogenetic results here support our hypothesis that LSU-B1 and LSU-B7 represent separate Clostridium species, which seem to be taxonomically distinct from $C$. puniceum.

Complementary insights into the relatedness of LSU-B1 and LSUB7 to known Clostridium spp. were provided by determination of their FAME profiles. Both isolates contained $\mathrm{C}_{16: 0}$ as their predominant fatty acid (Table 2), which is a characteristic typically shared by other Clostridium spp. (Inglett et al. 2011). Another fatty acid in abundance for both isolates was $\mathrm{C}_{14: 0}$, which was previously found to not be a major fatty acid for C. puniceum (Inglett et al. 2011). A distinguishing feature between LSU-B1 and LSU-B7 was the presence of $C_{16: 1} \omega 9 \mathrm{c}$ as a major fatty acid for the former but not the latter strain. Interestingly, it was previously determined (Inglett et al. 2011) that $\mathrm{C}_{16: 1} \omega 9 \mathrm{c}$ was also a major fatty acid for $C$. saccharoperbutylacetonicum (which clustered with LSU-B1 in the phylogenetic analyses above) but not for $C$. saccharobutylicum (which clustered with LSU-B7).

\section{Discussion}

Here, we characterized bacteria that were consistently isolated from soft rot lesions that developed on sweetpotato storage roots from an intentionally flooded field. Two representative strains were chosen for additional study. In accordance with Koch's Postulates, pure culture inocula of either strain reproducibly caused soft rot disease on sweetpotato as well as other vegetables, whereas mock-inoculated host plants never developed soft rot symptoms. In all pathogenicity assays, the inoculated strains were reisolated from the decaying plant tissue. To our knowledge, the ability of Clostridium isolates to cause disease indiscriminately on multiple plant hosts has not previously been demonstrated, and we hypothesize that such ability is likely a common feature of plant-pathogenic Clostridium spp. We also recognize the possibility that, during natural flooding events, multiple necrotrophic isolates, including strains LSU-B1 and LSU-B7 and potentially, other Clostridium strains and/or members of other species, may be coinfecting sweetpotato and perhaps at times, even cooperating in some manner to produce soft rot lesions (Abdullah et al. 2017).

Table 1. Results of plate assays to detect various hydrolytic enzyme activities by strains LSU-B1 and LSU-B7

\begin{tabular}{lcc}
\hline Enzyme activity $^{\text {a }}$ & LSU-B1 & LSU-B7 \\
\hline Pectinase & + & - \\
Amylase & + & - \\
Caseinase & - & + \\
Cellulase & - & + \\
\hline
\end{tabular}

a The presence of pectinase activity was screened on double-layer pectate medium agar, whereas amylase, caseinase, or cellulase functions were screened on nutrient dextrose agar plus $0.05 \%$ cysteine hydrochloride containing $1 \%$ soluble starch, $1 \%$ nonfat milk, or $1 \%$ carboxymethyl cellulose, respectively.
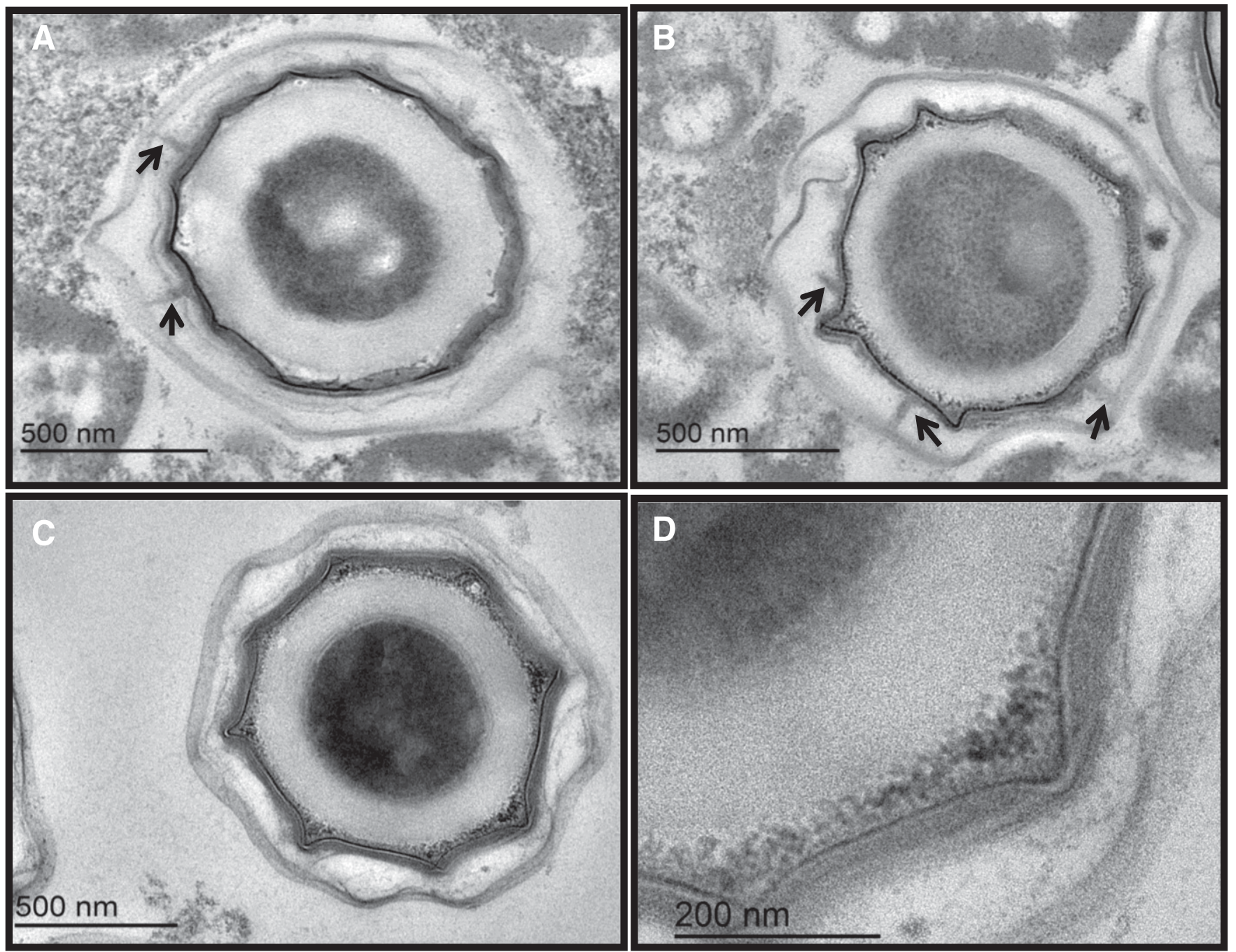

Fig. 1. Electron micrographs of LSU-B1 and LSU-B7 spores. After growth of sporulating cultures on potato infusion agar, spores were purified, embedded, and sectioned, and thin sections were stained with uranyl acetate and lead citrate before viewing. A and B, LSU-B1 spores. Arrows point to dark projections emanating from the LSU-B1 spore coat layer into the interspace. C, LSU-B7 spore. D, A magnified portion of the LSU-B7 spore shown in C that highlights the dark grainy material present at the outer edge of the cortex. 

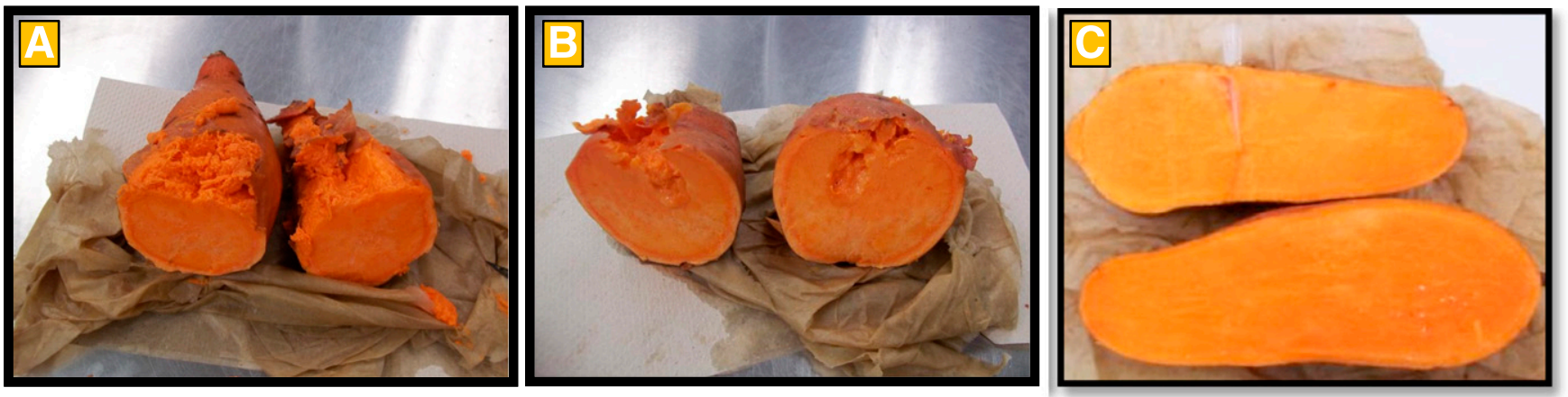

Fig. 2. Soft rot symptoms on cultivar Evangeline sweetpotato storage roots after inoculation with either LSU-B1 or LSU-B7. Intact storage roots were surface disinfested and inoculated by insertion of a pipette tip containing the indicated bacterial cell suspension, and roots were then incubated in an oxygen-limited environment at $30^{\circ} \mathrm{C}$ for 7 days. A, Inoculated with LSU-B1. B, Inoculated with LSU-B7. C, Mock-inoculated control.
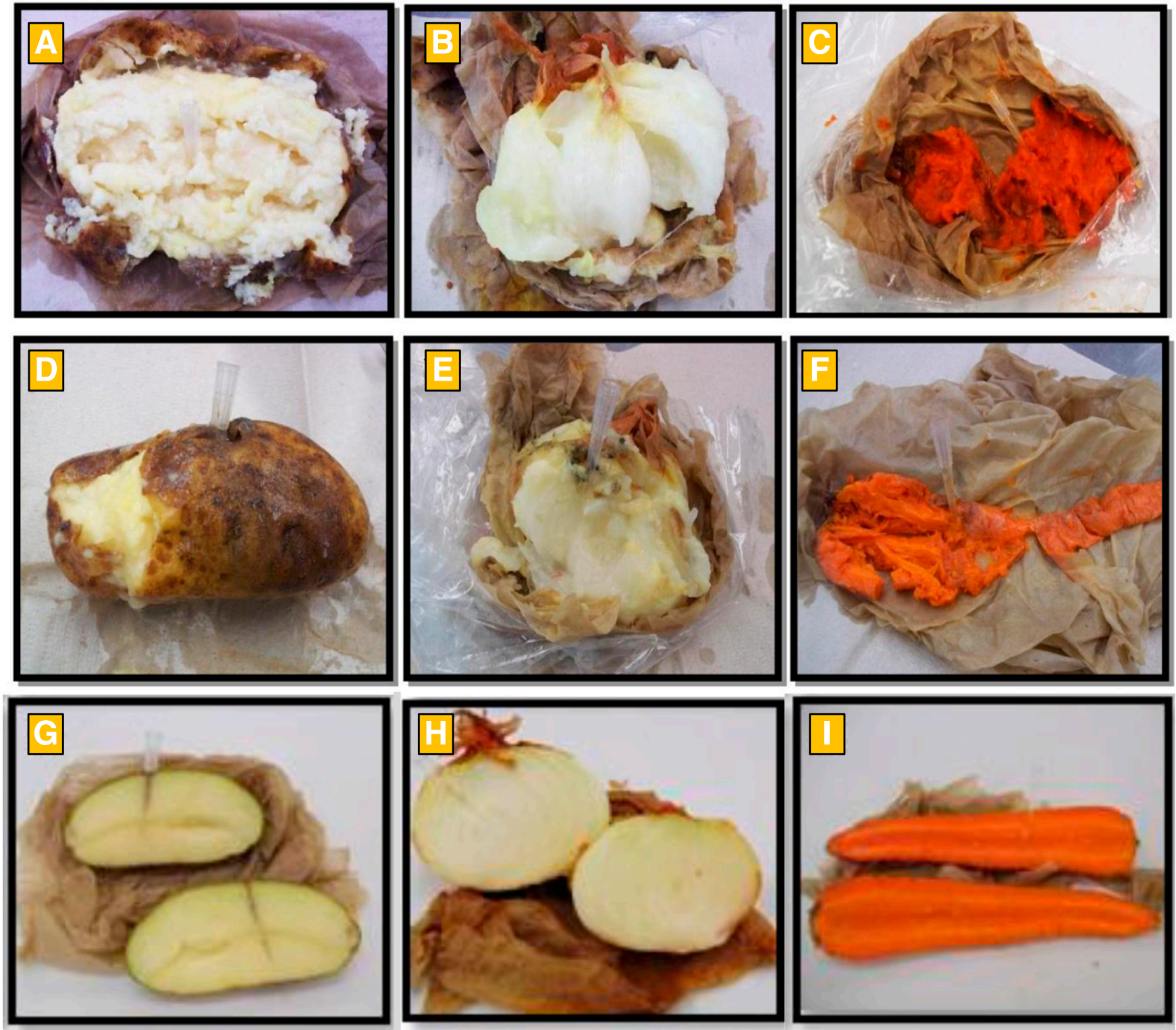

Fig. 3. Soft rot symptoms on other vegetables after inoculation with either LSU-B1 or LSU-B7. Asymptomatic, surface-disinfested whole potato tuber, onion bulb, and carrot root were inoculated with either LSU-B1 or LSU-B7 and then, incubated in an oxygen-limited environment at $30^{\circ} \mathrm{C}$ for 7 days. A, Potato, B, onion, and C, carrot inoculated with LSU-B1. D, Potato, E, onion, and F, carrot inoculated with LSU-B7. G, Potato, H, onion, and I, carrot mock-inoculated controls. 
Although both LSU-B1 and LSU-B7 were identified as anaerobic spore formers belonging to the genus Clostridium, they possessed distinguishing phenotypic and biochemical characteristics. Moreover, LSU-B1 clustered with the industrially important species $C$. saccharoperbutylacetonicum, whereas LSU-B7 grouped with another industrially relevant species $C$. saccharobutylicum in a separate clade, and neither isolate seemed to be as closely related to $C$. puniceum in several phylogenetic analyses. These findings support the hypothesis that multiple taxonomically distinct Clostridium spp. are capable of causing plant disease. Clarification of the relationships of LSU-B1 to C. saccharoperbutylacetonicum and LSU-B7 to $C$. saccharobutylicum awaits a more comprehensive understanding of their DNA-DNA relatedness (Stackebrandt and Goebel 1994). This could involve traditional wet laboratory DNA-DNA hybridization experiments, or after genome sequences become available for LSU-B1 and LSU-B7, their species identities could be determined by using comparable in silico-based analyses (Colston et al. 2014; Goris et al. 2007; Richter and Rossello-Mora 2009).

Pectolytic enzymes are the major disease determinants used by well-characterized soft rot pathogens, such as the genera Dickeya and Pectobacterium (Hugouvieux-Cotte-Pattat et al. 2014). In contrast, these pathogens do not breakdown starch via amylase (Kõiv et al. 2015), whereas the Clostridium isolate LSU-B1 here demonstrated that activity. Although hydrolysis of purified pectin in DLPM was not demonstrated by clostridial isolate LSU-B7, there is precedent for induction of bacterial pectolytic enzyme production only in planta (Toth et al. 2003); thus, future research could explore the possibility of pectinase (and amylase) production by LSU-B7 on sweetpotato storage root tissue. The potential for production of protease (e.g., caseinase) and cellulase activities for LSU-B1 in planta could be explored as well.

In potato, pectolytic clostridia and other bacteria capable of causing soft rot have been found primarily infecting lenticels (Perombelon et al. 1979), and when those lenticels proliferate under wet conditions, these microorganisms are able to penetrate into the tuber and initiate disease (Perombelon 2002). We have observed substantial lenticel proliferation on sweetpotato storage roots when those roots were submerged in water (data not shown). It is possible that, in flooded fields, the storage root lenticels proliferate and that these are the sites where Clostridium bacteria enter the root and start the infection. This scenario raises the possibility that finding an efficient way to control lenticel proliferation in sweetpotato storage roots could play a pivotal role in controlling the initiation of this soft rot disease. sweetpotato breeding programs could aim to select varieties that have minimum lenticel proliferation.

The identity of the dark grainy material observed at the cortex coat border for LSU-B7 spores (and to a lesser extent, LSU-B1 spores) is unknown but seems to be analogous to similar granules seen previously in Clostridium novyi NT spores (Plomp et al. 2007).

Although projections extending outward from the spore coat layer have also been observed previously (e.g., in Bacillus clausii spores) (Traag et al. 2010), we are unaware of any cases analogous to LSU$\mathrm{B} 1$, where projections appeared to contact both the spore coat and exosporium. It is tempting to speculate that such projections represent a type of physical connection (e.g., scaffolding) between the two layers.

The often harsh weather in the southeastern United States, with severe thunderstorms and hurricanes that cause flooding of crops, provides ideal conditions for the development of soft rot disease. In this study, we have provided valuable information about this disease

Table 2. Fatty acid composition of clostridial isolates LSU-B1 and LSU-B7

\begin{tabular}{lcc}
\hline Fatty acid (\%) & LSU-B1 $^{\mathbf{a}}$ & LSU-B7 \\
\hline $\mathrm{C}_{12: 0}$ & 1.06 & 0.00 \\
$\mathrm{C}_{14: 0}$ & $\mathbf{9 . 1 9}$ & $\mathbf{8 . 8 2}$ \\
Iso- $_{14: 0}$ & 0.12 & 0.00 \\
$\mathrm{C}_{16: 0}$ & $\mathbf{3 3 . 5 8}$ & $\mathbf{6 5 . 0 6}$ \\
$\mathrm{C}_{16: 0}$ aldehyde & 4.15 & 1.16 \\
$\mathrm{C}_{16: 0} \mathrm{~N}$ alcohol & 0.60 & 0.00 \\
$\mathrm{C}_{16: 1} \omega 5 \mathrm{c}$ & 0.11 & 0.00 \\
$\mathrm{C}_{16: 1} \omega 9 \mathrm{c}$ & $\mathbf{1 0 . 9 6}$ & 1.01 \\
$\mathrm{C}_{16: 1} \omega 7 \mathrm{c}$ & $\mathbf{1 3 . 3 4}$ & $\mathbf{8 . 2 3}$ \\
$\mathrm{C}_{17: 0}$ & 0.44 & 0.00 \\
$\mathrm{C}_{17: 0}$ cyclo $\omega 7 \mathrm{c}$ & 0.88 & 0.00 \\
$\mathrm{C}_{18: 1} \omega 7 \mathrm{c}$ & 4.07 & $\mathbf{6 . 1 3}$ \\
$\mathrm{C}_{18: 1} \omega 9 \mathrm{c}$ & 3.00 & 0.00 \\
$\mathrm{C}_{18: 0}$ & 3.51 & 3.53 \\
$\mathrm{C}_{19: 0}$ cyclo $\omega 7 \mathrm{c}$ & 1.60 & 1.08 \\
$\mathrm{C}_{19: 3} \omega 3 \mathrm{c}$ & 1.21 & 0.66 \\
\hline
\end{tabular}

${ }^{a}$ Major fatty acids ( $\left.>5 \%\right)$ are shown in bold. Fatty acids representing $<0.5 \%$ of the total are presented as zero.

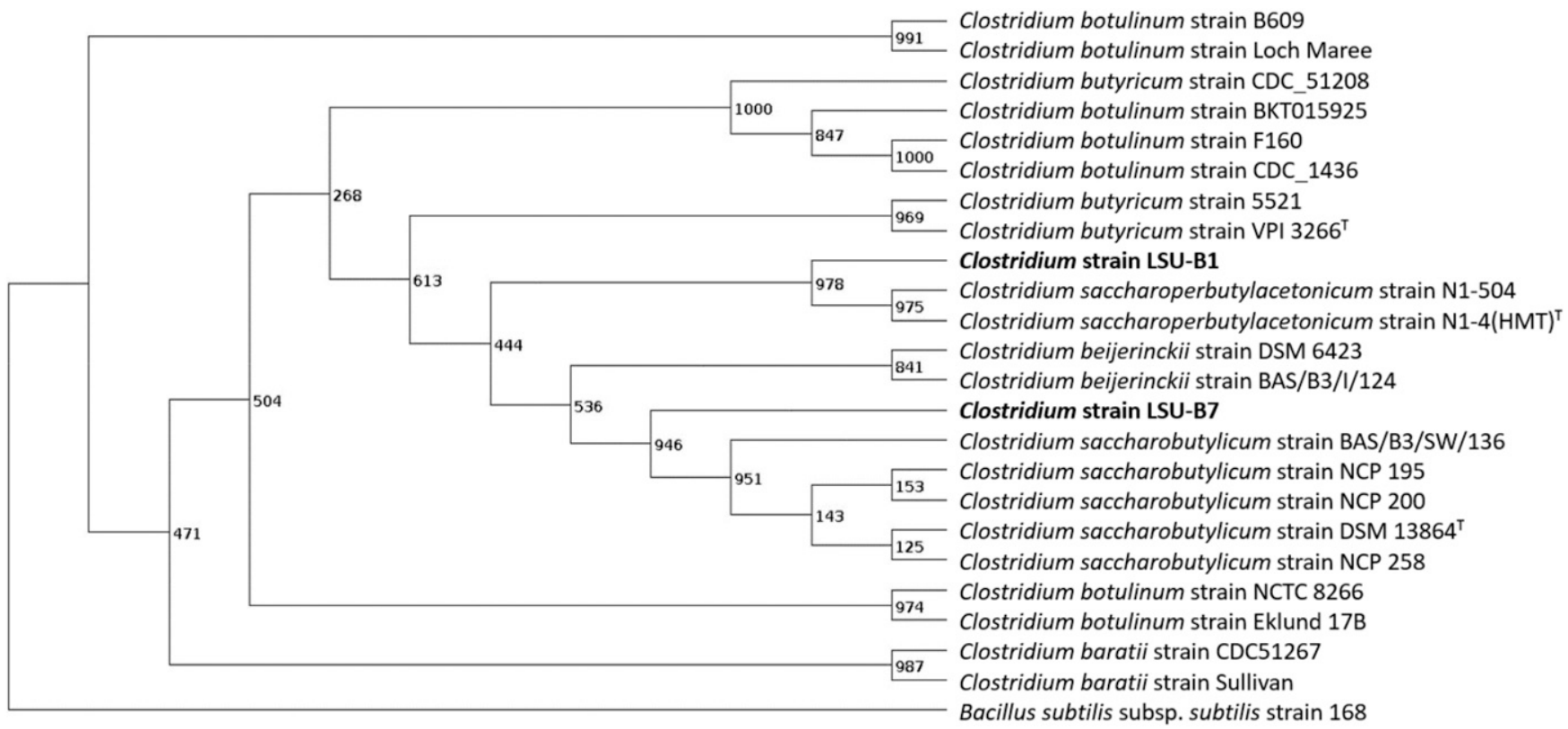

Fig. 4. Phylogenetic tree calculated from analysis of gyrA gene sequences using the maximum likelihood method with a general time-reversible plus gamma substitution model. Bootstrap support (based on 1,000 resamplings of the dataset) is presented at each node and was calculated by using the nearest neighbor interchange branch-swapping method. The type strain for a given species is denoted by the superscript $T$. 
etiology, which can be used as a foundation for developing strategies in disease management and control programs, giving better support to sweetpotato growers.

\section{Acknowledgments}

We are grateful to Lisa Fultz for assistance with fatty acid methyl ester analysis and Ying Xiao for her excellent technical assistance with transmission electron microscopy.

\section{Literature Cited}

Abdullah, A. S., Moffat, C. S., Lopez-Ruiz, F. J., Gibberd, M. R., Hamblin, J., and Zerihun, A. 2017. Host-multi-pathogen warfare: Pathogen interactions in coinfected plants. Front. Plant Sci. 8:1806.

Bauernfeind, A., and Burrows, J. R. 1978. Suggested procedure allowing use of plastic petri dishes in bacteriocin typing. Appl. Environ. Microbiol. 35:970

Bouillaut, L., McBride, S.M., and Sorg, J.A. 2011. Genetic manipulation of Clostridium difficile. Curr. Protoc. Microbiol. 20:9A.2.1-9A.2.17.

Bouvet, P., Ferraris, L., Dauphin, B., Popoff, M.-R., Butel, M.J., and Aires, J. 2014. 16S rRNA gene sequencing, multilocus sequence analysis, and mass spectrometry identification of the proposed new species "Clostridium neonatale." J. Clin. Microbiol. 52:4129-4136.

Campos, E., Maher, E. A., and Kelman, A. 1982. Relationship of pectolytic clostridia and Erwinia carotovora strains to decay of potato tubers in storage. Plant Dis. 66:543-546.

Castresana, J. 2000. Selection of conserved blocks from multiple alignments for their use in phylogenetic analysis. Mol. Biol. Evol. 17:540-552.

Colston, S. M., Fullmer, M. S., Beka, L., Lamy, B., Gogarten, J. P., and Graf, J. 2014. Bioinformatic genome comparisons for taxonomic and phylogenetic assignments using Aeromonas as a test case. MBio 5:e2136-14.

Edgar, R. C. 2004. MUSCLE: Multiple sequence alignment with high accuracy and high throughput. Nucleic Acids Res. 32:1792-1797.

Garnier, T., and Cole, S. T. 1986. Characterization of a bacteriocinogenic plasmid from Clostridium perfringens and molecular genetic analysis of the bacteriocinencoding gene. J. Bacteriol. 168:1189-1196.

Goris, J., Konstantinidis, K. T., Klappenbach, J. A., Coenye, T., Vandamme, P., and Tiedje, J. M. 2007. DNA-DNA hybridization values and their relationship to whole-genome sequence similarities. Int. J. Syst. Evol. Microbiol. 57:81-91.

Guindon, S., and Gascuel, O. 2003. A simple, fast, and accurate algorithm to estimate large phylogenies by maximum likelihood. Syst. Biol. 52:696-704.

Holdeman, L. V., Cato, E. P., and Moore, W. E. C. 1977. Anaerobic Laboratory Manual, 4th Ed. Anaerobe Laboratory, Virginia Polytechnic Institute and State University, Blacksburg, VA.

Hugouvieux-Cotte-Pattat, N., Condemine, G., and Shevchik, V. E. 2014. Bacterial pectate lyases, structural and functional diversity. Environ. Microbiol. Rep. 6: 427-440.

Inglett, K. S., Bae, H. S., Aldrich, H. C., Hatfield, K., and Ogram, A. V. 2011. Clostridium chromiireducens sp. nov., isolated from $\mathrm{Cr}(\mathrm{VI})$-contaminated soil. Int. J. Syst. Evol. Microbiol. 61:2626-2631.

Kõiv, V., Roosaare, M., Vedler, E., Kivistik, P. A., Toppi, K., Schryer, D. W., Remm, M., Tenson, T., and Mae, A. 2015. Microbial population dynamics in response to Pectobacterium atrosepticum infection in potato tubers. Sci. Rep. 5:11606.

Lund, B. M. 1969. (Symposium on Myxobacteria and Flavobacteria: Paper X). Properties of some pectolytic, yellow, pigmented, Gram positive bacteria isolated from fresh cauliflowers. J. Appl. Bacteriol. 32:60-67.

Lund, B. M. 1972. Isolation of pectolytic clostridia from potatoes. J. Appl Microbiol. 35:609-614.

Lund, B. M., Brocklehurst, T. F., and Wyatt, G. M. 1981. Characterization of strains of Clostridium puniceum sp.nov., a pink-pigmented, pectolytic bacterium. J. Gen. Microbiol. 122:17-26.

Lund, B. M., and Kelman, A. 2001. Clostridium. Pages 261-274 in: Laboratory Guide for Identification of Plant Pathogenic Bacteria. N. W. Schaad, J. B Jones, and W. Chun, eds. APS Press, St. Paul, MN.

McFaddin, J. F. 2000. Biochemical Tests for Identification of Medical Bacteria, 3rd Ed. Lippencott, Williams and Wilkens, Philadelphia, PA.

Obi, S. K. C. 1981. Pectinase activity of anaerobic and facultatively anaerobic bacteria associated with soft rot of yam (Diascorea rotundata). Appl. Environ. Microbiol. 41:563-567.

Perombelon, M. C. M. 2002. Potato diseases caused by soft rot erwinias: An overview of pathogenesis. Plant Pathol. 51:1-12.

Perombelon, M. C. M., Gullings-Handely, J., and Kelman, A. 1979. Population dynamics of Erwinia carotovora and pectolytic Clostridium spp. in relation to decay of potatoes. Phytopathology 69:167-173.

Perry, D. A., and Harrison, J. G. 1977. Pectolytic anaerobic bacteria cause symptoms of cavity spot in carrots. Nature 269:509-510.

Plomp, M., McCaffery, J. M., Cheong, I., Huang, X., Bettegowda, C., Kinzler K. W., Zhou, S., Vogelstein, B., and Malkin, A. J. 2007. Spore coat architecture of Clostridium novyi NT spores. J. Bacteriol. 189:6457-6468.

Pommerville, J. C. 2011. Alcamos Laboratory Fundamentals of Microbiology. Jones and Bartlett Learning, Sudbury, MA.

Reynolds, J., Moyes, R., and Breakwel, D. P. 2009. Differential staining of bacteria: Endospore stain. Curr. Protoc. Microbiol. 15:A.3J.1-A.3J.5.

Richter, M., and Rossello-Mora, R. 2009. Shifting the genomic gold standard for the prokaryotic species definition. Proc. Natl. Acad. Sci. USA 106:19126-19131.

Schink, B., Ward, J. C., and Zeikus, J. G. 1981. Microbiology of wetwood: Role of anaerobic bacterial populations in living trees. J. Gen. Microbiol. 123: 313-322.

Shabuer, G., Ishida, K., Pidot, S. J., Roth, M., Dahse, H. M., and Hertweck, C. 2015. Plant pathogenic anaerobic bacteria use aromatic polyketides to access aerobic territory. Science 350:670-674.

Stackebrandt, E., and Goebel, B. M. 1994. Taxonomic note: A place for DNADNA reassociation and 16S rRNA sequence analysis in the present species definition in bacteriology. Int. J. Syst. Bacteriol. 44:846-849.

Teather, R. M., and Wood, P. J. 1982. Use of Congo red-polysaccharide interactions in enumeration and characterization of cellulolytic bacteria from the bovine rumen. Appl. Environ. Microbiol. 43:777-780.

Toth, I. K., Bell, K. S., Holeva, M. C., and Birch, P. R. 2003. Soft rot erwiniae: From genes to genomes. Mol. Plant Pathol. 4:17-30.

Traag, B. A., Driks, A., Stragier, P., Bitter, W., Broussard, G., Hatfull, G., Chu, F., Adams, K. N., Ramakrishnan, L., and Losick, R. 2010. Do mycobacteria produce endospores? Proc. Natl. Acad. Sci. USA 107:878-881. 